\title{
La deuda externa: una mirada ética desde el punto de vista de sus efectos
}

\section{External debt: an ethical view from the point of view of its effects}

Felix E. Flores Flores $₫$

Universidad Nacional Mayor de San Marcos. Lima, Perú.

Recibido: 20-12-2018 Revisado: 19-03-2019 Aceptado: 11-05-2019 Publicado: 25 - 05-2019

\section{RESUMEN}

Los procesos de endeudamiento por parte de los estados han sido constantes y realizados por diversos motivos en diferentes países.

En el caso de países en proceso de desarrollo o con problemas para alcanzarlo, se han producido diferentes espacios para modificar el tipo de deuda y los procesos para pagarla.

Sin embargo, todo esto genera una problemática socioeconómica que afecta, especialmente, a ciudadanos de bajos recursos.

En el presente trabajo, se estudia a profundidad los procesos de endeudamientoy, principalmente, las modificaciones a los mismos por medio de las facilidades de pago. A su vez, se evalúa su impacto y se contrasta con una mirada ética de la problemática.

Palabras clave: bioética, ética, deuda externa.

\begin{abstract}
The processes of indebtedness on the part of the states have been constant and carried out for various reasons in different countries.

In the case of countries in the process of development or with problems to achieve it, different spaces have been created to modify the type of debt and the processes to pay it.

However, allthis generatesasocio-economic problemthataffects, especially,low-incomecitizens. In the present work, it is studied in depth the processes of indebtedness and, mainly, the modifications to them by means of the payment facilities. In turn, its impact is evaluated and contrasted with an ethical view of the problem.
\end{abstract}

Keywords: bioethics, ethics, external debt. 


\section{INTRODUCCIÓN}

Todos los países del mundo tienen algún tipo de deuda, tanto interna como externa, siendo que los países más adelantados son los que más deuda tienen en relación a la masa global del dinero, sin embargo, es más oneroso para aquellos países que tienen menor posibilidad de pago.

La deuda, desde el punto de vista de la economía, es una obligación que asume el deudor frente a un acreedor por un monto pactado por un tiempo determinado y una tasa acordada; el mismo que debe ser cumplido.

Esta definición sencilla de la deuda nos permite analizar en la deuda que asumen los países; con sus particularidades propias, como por ejemplo las condiciones de apertura económica, cambio de modelo económico, restricción en el uso de esta deuda, entre otros.

El aprovisionamiento de recursos mediante la deuda, en sí misma, es buena, porque permite insuflar en la economía liquidez que permite el emprendimiento de obras, el cumplimiento de obligaciones, ejecución de gastos corrientes, entre otros; sin embargo, cuando la deuda se contrae de manera desventajosa y de una manera rapaz, porque estas condiciones lo fijan los acreedores, tiene como consecuencia el empobrecimiento de los países con el añadido de que estos préstamos se efectúa bajo condicionamientos que socavan la soberanía nacional.

Los efectos de la deuda externa en sus distintas dimensiones, llámese económico, social, ético son difíciles de medir, sobre todo en el campo social y económico; quizás la explicación de que los países del tercer mundo sean justamente eso, países del tercer mundo; muchas de los préstamos se han de otorgar de manera ruinosa para el deudor.

El presente ensayo busca conocer las razones por las cuales llegamos a endeudarnos, bajo los conceptos antes indicado además de tener una aproximación de nuestra deuda actual y los efectos perniciosos que nos han acarreado a través del tiempo.

\section{ANTECEDENTES}

La deuda pública peruana está constituida por deuda externa y deuda interna; la deuda interna muchas veces se compone de bonos y de otros valores que el Estado coloca en el mercado interno; si el Estado emite bonos por $\mathrm{n}$ millones de soles que adquieren inversores nacionales.

Ese monto pasa a formar parte de su deuda interna, ya que en el plazo acordado deberá desembolsar ese dinero más los intereses correspondientes, la deuda externa, está relacionada con las deudas que un país tiene con entidades extranjeras, incluyendo tanto la deuda pública (contraída por el Estado) como la deuda privada (contraída por los particulares).

En el presente ensayo solo nos dedicaremos a estudiar la deuda externa, porque nuestros acreedores imponen muchas veces condiciones desventajosas para nuestro país.

La deuda externa contraída por el Perú se sucedieron a lo largo de nuestra vida republicana, los cuales se han ido acumulando; el primer préstamo extranjero fue por un monto de 1,2 millones de libras esterlinas a un interés del 6 por ciento anual, fue negociado en el boyante mercado londinense a comienzos de la década de 1820 por dos cuestionables enviados y amigos del general San Martín, el colombiano Juan 
García del Río y el médico británico James Paroissien. (Quiroz, 2013).

Este último, bien recompensado por el gobierno de San Martín con el rango militar de general y parte de una hacienda confiscada, estableció unas relaciones de negocios impropias e incompatibles con su misión en Londres.

Nuestro país, como se sabe, ha tenido una vida muy azarosa desde su nacimiento como país.

Lo anteriormente narrado responde a la financiación de las guerras de emancipación. Inglaterra y Francia fueron los principales acreedores de nuestra deuda, luego haremos un salto hasta las deudas adquiridas durante la guerra con Chile.

Nuestra economía era mala luego de la guerra con Chile porque se desató una guerra interna entre Andrés Avelino Cáceres y Nicolás de Piérola.

A inicios del siglo pasado, las deudas se fueron consolidando aún más, tanto los bancos ingleses como los franceses y los estadounidenses comenzaban ya a perfilarse: después de la segunda guerra mundial, comenzó a funcionar el Fondo Monetario Internacional, El Banco Mundial, así como también el Banco Interamericano de Finanzas, Corporación Andina de Fomento, Club de París así como organismos multilaterales, constantemente fuimos recurriendo a ellas para financiar la construcción de grandes obras.

De igual forma es de resaltar la deuda que se adquirió en la dictadura militar del general Juan Velasco Alvarado principalmente para adquirir armamento, a tal punto que nos convertimos en una potencia militar en este lado del mundo; luego de ello tenemos la crisis económica que sufrimos en el primer gobierno de Alan García Pérez en el que batimos record mundial en inflación de una manera infame.

La deuda externa excluye del desarrollo económico y social a los países endeudados en el mundo.

Este es un motivo más que suficiente para que este problema sea abordado desde un enfoque más humano, pues mantiene a más de la mitad de la población de los países endeudados en una lucha diaria por la sobrevivencia, como es el caso de nuestro país.

Es un asunto complejo que encierra muchos intereses económicos y políticos y que se mueve en un escenario de negociación regulado por la arbitrariedad de un juego de poderes definido por los acreedores y marcado por la desigualdad entre deudores y acreedores.

La deuda se ha convertido en un poderoso instrumento de dirección política a través del cual los países acreedores, bajo el liderazgo del Fondo Monetario Internacional (FMI), manejan a su criterio la política económica de los países deudores, dejando a éstos sin capacidad de respuesta ante las crisis internas e invadiendo su soberanía nacional.

\section{3.¿CÓMO ESTAMOS ACTUALMENTE?}

Es preciso poner de manifiesto que para el presente ensayo estamos tomando datos al año 2017, en tal sentido; la deuda externa del Perú está compuesta de la siguiente manera. 


\section{Deuda pública total: Saldo adeudado \\ (En millones de $\mathrm{S} /$ )}

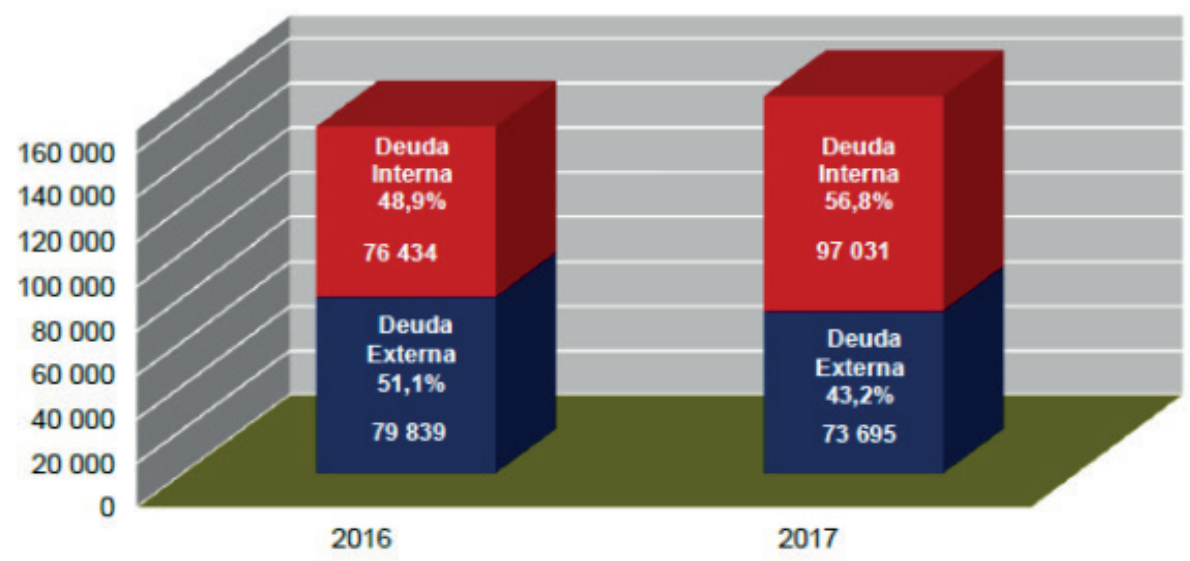

Figura 1. Fuente: D.Programación, Presupuesto y Contabilidad - DGETP

De acuerdo a su estructura contractual, el total de la deuda pública está pactada en 7 monedas y en 5 tipos de tasas de interés.

En relación a las monedas, el 58,2 \% está pactado en soles, el 34,3 \% en dólares estadounidenses y el 7,5\% en otras monedas. En cuanto al tipo de tasas de interés, las obligaciones han sido contratadas el 93,2\% a tasa fija y el 6,8\% a tasa variable.

Como la deuda ha sido contraída de diferentes países, también estas se han hecho en sus monedas nacionales, de forma que nuestra deuda está compuesta porcentualmente en las siguientes monedas:

\section{Deuda pública externa sin derivados: Saldo adeudado por monedas (En millones de $\mathrm{S} /$ )}

\begin{tabular}{|lr|}
\hline \multicolumn{1}{|c|}{ Monedas } & \multicolumn{1}{c|}{ Monto } \\
\hline Dólares & 58415 \\
Euros & 10117 \\
Yenes & 1726 \\
Otras & 3327 \\
Total deuda directa & 73585 \\
Deuda garantizada & 110 \\
Total & 73695 \\
\hline
\end{tabular}

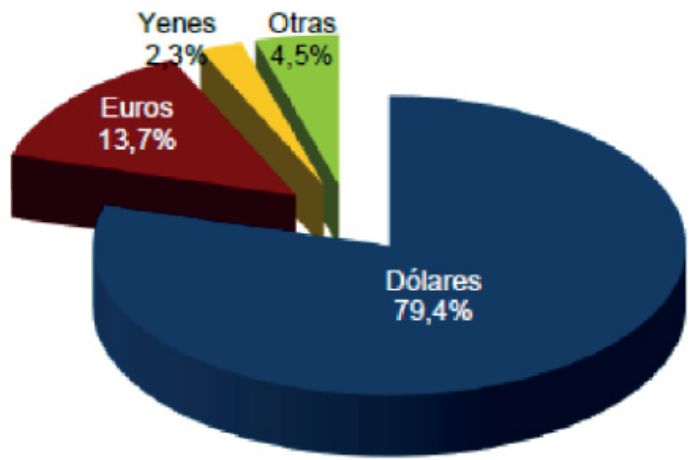

Figura 2. Fuente: D.Programación, Presupuesto y Contabilidad - DGETP 
Ahora, la deuda ha sido contraída de distinta fuente, entre ellas tenemos a los organismos multilaterales de crédito conformado principalmente por el Banco Mundial y el Fondo Monetario Internacional, el Club de París, conformado por distintos países como Alemania, Australia, Austria,
Bélgica, Canadá, Dinamarca, Estados Unidos, España, Finlandia, Francia, Irlanda, Italia, Japón, Noruega, Rusia, Holanda, Reino Unido, Suecia y Suiza, la Banca Comercial de Crédito conformada por bancos del exterior; es así que tenemos la siguiente distribución:

\section{Deuda pública externa sin derivados: Saldo adeudado por fuente de financiamiento} (En millones de S/)

\begin{tabular}{|lr|}
\hline \multicolumn{1}{|c}{ Fuente financiera } & \multicolumn{1}{c|}{ Monto } \\
\hline Bonos & 56898 \\
\hline Multilaterales & 12536 \\
Club de París & 3686 \\
Banca Comercial & 439 \\
Proveedores & 26 \\
\hline Total deuda directa & 73585 \\
Deuda garantizada & 110 \\
Total & 73695 \\
\hline
\end{tabular}

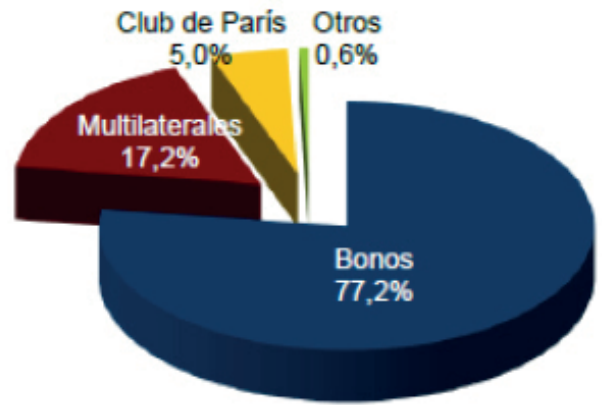

Figura 3. Fuente: D.Programación, Presupuesto y Contabilidad - DGETP

Al interior del rubro Bonos, destacan los globales con el 99,7 \%, mientras que el remanente corresponde al bono Brady PAR que cuenta con un saldo de S/ 174,2 millones.

El Banco Interamericano de Desarrollo - BID (S/ 4 229,1 millones) conjuntamente con el Banco Mundial - BIRF (S/ 3 522,3 millones) representan el $61,8 \%$ de la deuda que se mantiene con los organismos multilaterales.

En lo que concierne a las deudas con los países miembros del Club de París, Alemania y Japón son nuestros principales acreedores con el 50,5\%, y el 39,5\% respectivamente. (Finanzas, 2018).
Nuestro país viene enfrentando los pagos de nuestras deudas mediante dispositivos que se dictan cada año a través de la Ley del Presupuesto Público de los años correspondientes; de la revisión del portal Consulta Amigable del Ministerio de Economía y Finanzas hemos elaborado el siguiente cuadro que revela lo que estamos pagando en el presente ejercicio fiscal 2018: 


\begin{tabular}{|c|c|}
\hline SERVICIO DE LA DEUDA PUBLICA - ENDEUDAMIENTO EXTERNO & $4,175,852,212$ \\
\hline 1: AMORTIZACION DE LA DEUDA & $1,281,919,965$ \\
\hline 5: CORPORACION ANDINA DE FOMENTO - CAF & $473,179,477$ \\
\hline 2: BANCO MUNDIAL - BIRF & $360,974,347$ \\
\hline 9: AGENCIA DE COOPERACION INTERNACIONAL DEI JAPON - JICA & $153,799,155$ \\
\hline 1: BANCO INTERAMERICANO DE DESARROLLO - BID & $132,389,358$ \\
\hline 4: KREDINTANSTALF FUR WIEDERAUFBAU - KFW & $125,429,758$ \\
\hline 4: OTRAS AMORTZACIONES EXTERNAS & $12,789,918$ \\
\hline 99: OTROS ORGANISMOS INTERNACIONALES O AGENCIAS OFICIALES & $12,672,998$ \\
\hline 6: FONDO INTERNACIONAL DE DESARROLLO AGRICOLA - FIDA & $9,199,468$ \\
\hline 1: PROVENIENTES DE GOBIERNOS EXTRANUEROS & $1,485,486$ \\
\hline 2: INTERESES DE LA DEUDA & $2,811,107,175$ \\
\hline 3: DE TITULOS VALORES COLOCADOS EN El EXTERIOR (BONOS) & $2,353,217,274$ \\
\hline 2: PROVENIENTES DE ORGANISMOS INTEENACIONALES O AGENCIAS OFICIALES & $456,330,199$ \\
\hline 4: OTROS INTERESES EXTERNAS & $1,357,620$ \\
\hline 1: PROVENIENTES DE GOBIERNOS EXTRANJEROS & 202,082 \\
\hline 3: COMISIONES Y OTROS GASTOS DE LA DEUDA & $82,825,072$ \\
\hline 2: PROVENIENTES DE ORGANISMOS INTERNACIONALES O AGENCIAS OFICIALES & $72,608,767$ \\
\hline 5: OTROS GASTOS DE LA DEUDA EXTERNA & $6,540,302$ \\
\hline 3: DE TITULOS VALORES COLOCADOS EN EI EXTERIOR & $3,671,003$ \\
\hline 4: OTRAS COMSIONES EXTERNAS & 5,000 \\
\hline
\end{tabular}

Figura 4. Estado de la deuda pública

Como se puede apreciar del cuadro, se desprende los siguientes porcentajes para el servicio de la deuda, teniendo:

Amortización........30.70 \%
Intereses...............67.32 \%
Comisiones...........1.98 \%

Es decir, más de la mitad de la deuda es por intereses, solo un tercio corresponde al principal o la reducción del capital de la deuda, de lo cual queda un porcentaje por concepto de comisiones, principalmente por la colocación de los bonos en el mercado externo y que son pagados a bancos del exterior, los bancos colocadores de bonos cobran comisiones abusivas, puesto que no tiene en cuenta la dificultades que pasan los países pobres.

\section{LAS OTRAS DEUDAS QUE GENERA LA DEUDA EXTERNA}

Si bien la deuda es enteramente económica, sus efectos en los países deudores sufren sus consecuencias en distintas formas teniendo los siguientes.

\subsection{Deuda social}

Para entender el impacto de la deuda en las sociedades, se debe tener en cuenta que los países postergan su desarrollo privilegiando el pago de las deudas en contra de los habitantes que buscan desarrollo, mejora de viviendas obras de saneamiento entre otras muchísimas iniciativas postergadas.

Esto tiene un tremendo coste puesto que este espiral parece nunca terminar, de ahí que se ha acuñado la frase: Deuda externa = a deuda eterna.

La deuda social es una deuda de libertad, de todas las libertades que le han sido privadas a millones de personas que hoy día no pueden optar a un futuro mejor a un destino sin pobreza. 
Es necesario que los acreedores y las IFI reconozcan y asuman el daño que han producido sobre las economías endeudadas con el establecimiento de sus planes de ajuste y la política del miedo, bajo la amenaza del corte del flujo financiero internacional.

Hasta que no asuman esta cara del problema de la deuda, la cara social, y apliquen medidas definitivas para su solución, todas las demás medidas serán simples placebos que acrecentarán la brecha entre los países.

Pero tampoco podemos dar toda la responsabilidad al pago de la deuda, a los planes de ajuste propuestos por los organismos internacionales ni a los acreedores.

Los gobiernos también contribuyen a esta situación por la aplicación de políticas de desarrollo dependientes del exterior, por las medidas populistas de acción social que emplean para ganar los votos de las mayorías empobrecidas y que no generan desarrollo sino dependencia, los elevados niveles de corrupción, la debilidad de las políticas fiscales que no promueven una distribución del ingreso, y la ausencia de un plan país coherente, íntegro y asumido por el Estado y la sociedad civil de manera que los cambios de gestión no supongan un deshacer lo andado.

Por poner un ejemplo, en Perú cada gobierno de turno ha cambiado anualmente y hasta dos veces al año en algunas ocasiones, al ministro de educación, ¿es así posible construir un plan educativo sólido para el país si cada ministro desconoce lo que hizo el anterior?, ¿es así posible construir un país?

\subsection{Deuda odiosa o ilegítima}

El jurista ruso Alexander Nahum Sack en 1898 acuñó la frase de deuda odiosa o ilegítima. Si un poder despótico incurre en una deuda no por las necesidades o los intereses del Estado, sino para otorgar mayor fuerza a su régimen despótico, para reprimir a la población que se le enfrenta, etc., esta deuda es odiosa para la población de todo el Estado.

Esta deuda no es una obligación para la nación; es una deuda del régimen, una deuda personal del poder que la ha tomado, por lo tanto ésta cae con la caída del poder que la tomó.

La razón por la que no se puede considerar que estas deudas odiosas graven el territorio del Estado es que dichas deudas no cumplen con una de las condiciones que determinan la legalidad de las deudas del Estado, que dice: las deudas del Estado deben ser tomadas y los fondos deben ser empleados para satisfacer la necesidades y los intereses del Estado. (Ramos, 2006).

Generalmente estas deudas se han dado en los casos de dictaduras militares.

Los países adquieren deudas al margen de los intereses de la población y con el pleno conocimiento del acreedor. Existen dos clasificaciones:

- El gobierno del país recibe un préstamo sin el conocimiento ni la aprobación de los ciudadanos.

- El préstamo se destina a actividades no beneficiosas para el pueblo. aunque el prestamista está informado de la situación descrita en los puntos anteriores concede el préstamo -normalmente por el alto interés que recibirá-.

Son muchas las iniciativas que se han tomado a través de organizaciones internacionales para la abolición de estas deudas, muchos se han logrado eliminar tenemos el caso por ejemplo de: 
- MEXICO AUSTRIA: En 1861, Benito Juárez decretó la congelación del reembolso por dos años de la deuda externa contraída por el dictador Antonio López de Santa Ana.

En 1883, México promulgó la Ley para la consolidación y conversión de la deuda nacional, que denunciaba la deuda contraída de 1857 a 1860 y de 1863 a 1867; estos últimos fueron créditos usureros utilizados por el emperador Maximiliano de Austria para asegurar su imperio; en base de esta ley se declaraba toda esta deuda nula y odiosa.

-NORUEGA - ECUADOR: La decisión tomada por el Gobierno Noruego en octubre del 2006 de cancelar "los 500 millones de coronas de deudas oficiales de Ecuador, Egipto, Jamaica, Perú y Sierra Leona, que se originaron en la Campaña de Exportación de Naves Noruegas (1976-1980)".

Marcó un hito en la lucha contra la ilegitimidad de la deuda externa que pesa sobre los países del Sur. Esta valiente iniciativa del Gobierno de Noruega crea un precedente importante, ya que reconoce su corresponsabilidad y señala un ejemplo que tendría que ser seguido por otros países del Norte y los organismos multilaterales. (Alberto Acosta, 2008).

De acuerdo a los ejemplos anteriores toda deuda considerada odiosa o ilegítima puede impugnarse porque ya tenemos precedentes favorables; en estos tiempos adquirir deudas de este tipo serían inviables, puesto que los bancos difícilmente prestarían sabiendo que puede ser impugnada.

\subsection{Deuda ecológica}

El concepto de deuda ecológica es relativamente nuevo y los defensores del mismo abogan por el intercambio de deuda externa por deuda ecológica. Es un punto de partida interesante pero su negociación con los acreedores es aún débil pues no se han establecido mecanismos para cuantificar esa deuda ecológica.

Sí se han dado, sin embargo, algunos pasos, aún insuficientes, en el alivio de deuda por inversión en proyectos de protección medioambiental, pero sería más efectivo realmente cambiar las prácticas destructivas del actual sistema.

Esta forma de nivelar las cuentas o saldarlas es lo único que tenemos los países pobres para poder negociar la deuda, lo importante es que se ha puesto en discusión esta posibilidad, ahora veamos cuales serían los tópicos para poder iniciar esta discusión más abiertamente:

- LA DEUDA POR EXTRACCIÓN DE RECURSOS La Deuda Ecológica involucra el reclamo de la deuda que los países del norte tienen con los países del dur, por la extracción y exportación de bienes naturales del sur, tales como el petróleo, minerales, bienes forestales, marinos y genéticos que en su proceso de extracción están destruyendo los ecosistemas y la base de sobrevivencia de los pueblos.

Desde la revolución industrial, hasta la actualidad, ha existido un intercambio ecológicamente desigual, pues materias primas son exportadas sin tomar en cuenta los daños sociales y ambientales, locales y globales.

Grandes compañías transnacionales se han instalado en el tercer mundo, por la mano de obra barata, por los pocos controles sobre los impactos sociales y ambientales, los bienes naturales disponibles y las políticas domésticas que favorecen la inversión extranjera, produciendo desastres irreversibles. 
Ejemplos conocidos son los de la Texaco, en Ecuador, la Southern Perú Copper Corporation en Péru, Cambior en Guyana, el consorcio de Dow Chemicals, Occidental Petroleum, Standard Fruit, United Fruit y Shell, en Costa Rica, entre otros.

\section{- APROPIACIÓN INTELECTUAL DE} CONOCIMIENTOS ANCESTRALES

La Deuda Ecológica también involucra el reclamo de la deuda que los países industrializados del norte tienen con el tercer mundo por la apropiación intelectual, histórica y actual, de los conocimientos ancestrales.

Los principales conocimientos apropiados ilegalmente e ilegítimamente son aquellos relacionados con el mejoramiento de las semillas, uso de plantas medicinales y otros conocimientos sobre los que se sustenta la biotecnología y la agroindustria moderna, por la que se tienen que pagar regalías.

Los países del norte se han enriquecido por medio de la apropiación comercial de la diversidad biológica extraída en los centros de origen de los cultivos y de biodiversidad silvestre y de su conocimiento vinculado.

El exsecretario de Estado de los Estados Unidos Warren Christopher valoró en 7.000 millones de dólares el aporte hecho por el germoplasma de maíz extranjero a la economía de los Estados Unidos.

Sin embargo, desde que el maíz entró a formar parte de las negociaciones comerciales, del NAFTA, en 1994, millones de agricultores, principalmente en México, se han visto afectados por la importación de maíz desde Estados Unidos, por otro lado, se calcula que el valor del germoplasma del tercer mundo que usa la industria farmacéutica asciende a 47.000 millones de dólares.
- USO DE BIENES Y SERVICIOS NATURALES COMO SUELOS, AGUA, AIRE, ETC.

La Deuda Ecológica involucra el reclamo de la deuda que los países del norte tienen con los países del tercer mundo por el uso y la degradación de las mejores tierras, del agua y del aire, y de la energía humana.

Los países del sur, por sobre el objetivo de satisfacer primero las necesidades básicas, destina bienes y servicios, para establecer cultivos de exportación, poniendo en riesgo la seguridad y soberanías alimentarias y culturales de las comunidades locales y nacionales.

En América Latina y el Caribe, por ejemplo, el actual modelo de desarrollo se basa en el aumento de exportaciones, de materias primas, y de productos agrícolas, etc.

Son monocultivos extensivos e intensivos, con grandes capitales nacionales y extranjeros, que utilizan las mejores tierras, el agua y la mano de obra campesina mal pagada para productos de exportación.

Es una paradoja que países agrícolas de la región, tengan niveles de desnutrición que pueden llegar en algunos casos a más del $50 \%$ de la población, mientras figuramos como los grandes exportadores de proteínas, vitaminas y minerales en los alimentos que exportamos.

\section{- LA DEUDA DE CARBONO}

La Deuda Ecológica involucra el reclamo de la deuda que los países del norte tienen con el tercer mundo por la apropiación de la atmósfera y de la capacidad de absorción de carbono del planeta.

Los países del norte son los principales responsables del calentamiento global, y 
de los cambios climáticos, debido a las desproporcionadas cantidades de dióxido de carbono emitidas por sus industrias, y la quema de combustibles fósiles, fuente de energía de un modelo de vida no sustentable.

Los impactos de los cambios climáticos a nivel local y global se expresan en la disminución de las lluvias, inundaciones, desertificación, más fuertes y frecuentes fenómenos climáticos como huracanes, el Niño, tormentas, etc., el descongelamiento de los polos y la elevación del nivel de las nieves perpetuas.

Los impactos se traducen en pérdida de vidas humanas y de cultivos agrícolas, destrucción de infraestructura vial y de viviendas.

Para prevenir y reconstruir estos daños, muchas veces los estados del sur tienen que recurrir al endeudamiento externo.

-DEUDA POR PRODUCCIÓN DE RESIDUOS TÓXICOS, ARMAS QUÍMICAS Y NUCLEARES La Deuda Ecológica involucra el reclamo de la deuda que los países industrializados del norte tienen con los países del tercer mundo por la producción de residuos tóxicos, armas químicas y pruebas y desechos nucleares.

Los países del norte han convertido en el basurero de sus residuos tóxicos a muchos países del sur.

Todos los efectos sociales y ambientales de los productos de muerte y los residuos tóxicos producidos en el norte son parte de la Deuda Ecológica pues ponen en riesgo al conjunto del planeta y a las poblaciones locales en donde se deposita su basura tóxica.

\section{- LA RELACIÓN ENTRE DEUDA EXTERNA Y DEUDA ECOLÓGICA}

Para cumplir con las obligaciones y los intereses de la deuda externa, los países del tercer mundo se ven presionados a exportar más y más recursos, generándose más deuda ecológica.

El volumen de exportaciones de América Latina han aumentado en quince años, desde 1980 hasta 1995 en un $245 \%$.

Desde 1985 y 1996, en doce años, se habrían extraído y enviado al exterior 2.706 millones de toneladas de productos básicos, la mayoría de ellos no renovables.

No se ha calculado aún cuánto material se transforma, destruye o mueve para lograr estas exportaciones, ni cuánta población ha sido afectada o desplazada.

Como ejemplo podemos citar que mientras que desde 1982 hasta 1996, en catorce años, América Latina ha reembolsado 739.900 millones de dólares, es decir más del doble de lo que debía en 1982 que era 300.000 millones de dólares y sin embargo la deuda no ha disminuido sino que ha aumentado a 607.230 millones de dólares, debido a una clara especulación en los mercados financieros.

\section{INICIATIVA PPAE}

En inglés: Heavily Indebted Poor Countries - Países Pobres Altamente Endeudados conforman un grupo de países que se beneficia de la llamada iniciativa HIPC, creada por el G8 para aquellos países con alta deuda pública (principalmente situados en África, Asia y Latinoamérica).

Fue adoptada en 1996 por el Fondo Monetario Internacional y el Banco Mundial para reducir la carga de la deuda de los países pobres a un nivel considerado como sostenible (esto es, que el desarrollo de un país no se vea 
afectado como consecuencia de las cargas derivadas de la deuda: principal e intereses).

Para beneficiarse de esta iniciativa, a los países altamente endeudados se les exige, entre otros requisitos, la firma de un documento de estrategia de lucha contra la pobreza.

1. Ser considerado potencialmente elegible por el FMI y el Banco Mundial, en base a una combinación de criterios de deuda y pobreza. En la actualidad, sólo 39 países reúnen los requisitos.

2. Punto de Decisión.- El país es elegido por el FMI/BM para beneficiarse del alivio de la deuda, gracias a cumplir con los requisitos exigidos: deuda "insostenible", desarrollo de un documento de estrategia de lucha contra la pobreza, haber emprendido las reformas recomendadas por el FMI/ BM. 36 de los 39 países potencialmente elegibles han sido provisionalmente declarados beneficiarios de la iniciativa.

3. Punto de Culminación.- El cumplimiento de unos requisitos extras permiten al país endeudado pasar de ser beneficiario "provisional" de la iniciativa a beneficiario pleno, lo que implica una reducción plena e irrevocable de la deuda. De los 36 países antes indicados, 35 ya son beneficiarios plenos y uno, Chad, está en fase de transición.

\section{CONDONACIÓN DE LA DEUDA}

En 1986, el Pontificio Consejo de Justicia y Paz elaboró un documento titulado "Al servicio de la comunidad humana: una consideración ética de la deuda internacional" donde se afirmaba que "El servicio de la deuda no puede ser satisfecho al precio de una asfixia de la economía de un país".

Ningún gobierno puede exigir moralmente de su pueblo que sufra privaciones incompatibles con la dignidad de las personas" (ETCHEGARAY, 1986).

Conjuntamente con esta iniciativa eclesiástica se ha conformado una red que agrupa organizaciones sociales de todas partes del mundo denominado Jubileo 2000, quienes propiciaron la discusión de la deuda externa en los países empobrecidos. Se buscaba el perdón de esta deuda, asimismo en el año 2000 la ONU aprobaba la Declaración del Milenio.

Uno de sus acápites pedía a los países industrializados que apliquen sin más demora el programa mejorado de alivio de la deuda de los países pobres muy endeudados y que convengan en cancelar todas las deudas bilaterales oficiales de esos países a cambio de que éstos demuestren su firme determinación de reducir la pobreza. (Unidas, 2000).

Es así que el año 2008 el G8, conformado por los países más ricos del mundo (Estados Unidos, Japón, Alemania, Francia, Italia, Canadá, Rusia y el Reino Unido), han acordado aliviar las deudas de 18 de los países más pobres del mundo, 14 africanos y 4 en América.

El Fondo Monetario Internacional, el Banco Mundial y el Fondo de Desarrollo para África cancelarán todo el dinero que los países seleccionados les deban, suma que estaría cerca de los 40 mil millones de dólares.Estas instituciones deberán aprobar el acuerdo.

La lista de países beneficiados está conformada por Benín, Bolivia, Burkina Faso, Etiopía, Ghana, Guyana, Honduras, Madagascar, Malí, Mauritania, Mozambique, Nicaragua, Níger, Ruanda, Senegal, Tanzania, Uganda y Zambia. 


\section{REGULACIÓN NORMATIVA DEL ENDEUDAMIENTO EXTERNO CASO PERUANO}

En nuestro país tenemos normativamente la Ley No 285631 Ley General del Sistema Nacional de Endeudamiento promulgada el 23 de junio de 2005, que a su vez dispone que cada año se fijen los topes de endeudamiento.

Establece además que Las operaciones de endeudamiento y las operaciones de administración de deuda se aprueban con arreglo a lo dispuesto por la presente Ley, las Leyes de Endeudamiento del Sector Público que se aprueban anualmente y las directivas que emita la Dirección General de Endeudamiento y Tesoro Público, bajo sanción de nulidad y sin perjuicio de la responsabilidad personal de quienes la realicen, es decir la responsabilidad y aprobación de la deuda depende del Poder Ejecutivo a través de la Dirección General de Endeudamiento y Tesoro Público del Ministerio de Economía y Finanzas.

Creemos que toda deuda externa que se contraiga a raíz de las experiencias negativas que tuvimos en el pasado debe pasar obligatoriamente por el Congreso de la República puesto que la deuda será pagada por todos nosotros.

\section{CRÍTICA AL ENDEUDAMIENTO EXTERNO}

En primer término, tenemos un fondo denominado Fondo de Estabilización Fiscal que al año 2017 alcanzó los US \$ 6,398,461,362.38, estos fondos son administrados por un directorio compuesto por tres miembros, presidido por el Ministro de Economía y Finanzas e integrado por el presidente del BCR y por un representante designado por la PCM, todos del Poder Ejecutivo.

Este fondo proviene básicamente de:

- Saldo presupuestal positivo de libre disponibilidad de Tesoro Público, obtenido al final de cada año fiscal, en la fuente de financiamiento Recursos Ordinarios.

- El $10 \%$ de los ingresos líquidos de las operaciones de venta de activos por privatizaciones.

- El $10 \%$ de los ingresos líquidos del pago inicial por concesiones del Estado. Durante el año 2015, se transfirieron US\$ 3,15 millones por concepto de concesiones (Hotel de Machu Picchu, proyecto minero Toromocho, proyecto especial Chinecas, proyecto minero Las Bambas, proyecto minero Michiquillay, proyecto minero La Granja, proyecto minero Salmueras).

- Intereses por los depósitos a plazo del FEF en el BCRP. Por concepto de intereses los depósitos a plazo del FEF en el BCRP, generaron US\$11,23 millones.

En segundo término tenemos las Reservas Internacionales Netas -RIN que tiene el Banco Central de Reserva del Perú (BCRP) y su objetivo principal es respaldar los billetes/soles que hay en circulación en la economía peruana, al año 2017 se tenía US \$ $63731,000,000.00$.

De una simple suma tenemos:

FEF US $\$ 6,398,461,362.38$

$\begin{array}{ll}\text { RIN } & \text { US \$ 63,731,000,000.00 } \\ \text { Total } & \text { US } \$ 70,129,461,362.38\end{array}$

Es decir, tenemos liquidez suficiente como para tener que recurrir a deudas que son realmente los yugos que frenan nuestro desarrollo, sin embargo, cada año contraemos más y más deuda.

Prueba de ello son los topes que se fijan cada año para acceder a estas, con los cuales la 
deuda externa se convierte en deuda eterna. creemos que los bancos centrales y los organismos multilaterales impulsan que los países se endeuden para que tengan "historial crediticio" y sean bien vistos por la banca internacional; para ello también están diseñados los índices de Riesgo País, con los cuales nos manipulan a su antojo.

\section{CONCLUSIONES}

- Los préstamos tanto de dinero como de recursos no es algo nuevo en nuestras sociedades. La cuestión aquí es la dimensión ética del préstamo, critico la forma como los países ricos condicionan los préstamos a los países pobres sin tener contemplación del desarrollo de los pueblos, que legítimamente como todo ser humano tiene pleno derecho a coexistir en este planeta, la función del dinero es estar al servicio del hombre, no al revés, pareciera que los seres humanos son objetos de intermediación para la acumulación de riquezas, las deudas por lo general están diseñadas para que sean eternas.

- La deuda externa impide el desarrollo de los pueblos del mundo, no por la deuda en si misma sino por lo intereses expoliadores que a lo largo de la historia han arruinado a los países, impidiendo su progreso, lo cual retrasa el desarrollo, comprometiendo los exiguos recursos con tal de cumplir con las deudas.

- La deuda ecológica es una corriente de opinión que han ido consolidando los países pobre frente a adeuda, básicamente significa que a los largo de los años la países acreedores san ido dejando negativas huellas en el medio ambiente como en la sociedad, por ejemplo, al extraer recursos como los minerales han dejado o están dejando sitios inhabitables, infértiles, se llevan el recurso y nos dejan los deshechos ejemplo las minas de cerro de Pasco, también la apropiación de costumbres ancestrales, la contaminación del medio ambiente, el único problema aquí es que no hay consenso de la forma de calcular esta deuda.

- Desde distintos frentes se han alzado voces como las de iglesia católica, movimientos sociales, gobiernos que aprovechan el Jubileo 2000 con tal de que los países ricos puedan condonar la deuda de los países más pobres, logrando que en año 2005 se emita un deseo del G-8 la condonación de cerca de 40 mil millones de dólares.

- Nuestro país en la actualidad tiene una deuda externa de aproximadamente 74 mil millones de dólares americanos, estamos considerados como país de ingresos medios, somos además el que menos debe en Sudamérica, en total la deuda pública del Perú que abarca tanto deuda interna como externa es de aproximadamente 171 mil millones de Dólares Americanos, según los últimos estudios para saldar la deuda del Perú tendríamos que pagar cada peruano alrededor de S/ 5,398.

- Si el Perú tiene recursos disponibles como los del Fondo de Estabilización Fiscal y de Reservas Internacionales Netas, que sumados dan aproximadamente 70 mil millones de dólares americanos no tendría necesidad de recurrir a la banca internacional a adquirir prestamos no por el capital en sí mismo, sino para evitar pagar los intereses, nuestra legislación permite año tras año adquirir nueva deuda sin que se discuta por ejemplo en 
el congreso, la potestad le corresponde únicamente al poder ejecutivo, conviene revisar estos modos de adquirir deuda.

\section{REFERENCIAS BIBLIOGRÁFICAS}

Acosta, H. A. (2008). Sobre la deuda ilegítima, aportes al debate Argumentos entre consideraciones. Quito: CIUDAD Centro de Investigaciones/Observatorio de la Cooperación.

Etchegaray, R. C. (27 de Diciembre de 1986). www.vatican.va. Obtenido de www.vatican. va: http://www.vatican.va/roman_curia/ pontifical_councils/justpeace/documents/rc_ pc_justpeace_doc_19861227_debito_sp.html.

MEF (2018). Informe Anual de Deuda Pública 2017. Lima: Ministerio de Economía y Finanzas.

Quiroz, A. W. (2013). Historia de la Corrupción en el Perú. En A. W. Quiroz, Historia de la Corrupción en el Perú. Lima: Instituto de Defensa Legal.

Ramos, L. (2006). Los crímenes de la deuda: deuda ilegítima. Barcelona : Icaria editorial s.a. Unidas, O. d. (2000). 55/2. Declaración del Milenio. Nueva York: ONU. 